\title{
Ventricular Tachycardia in Structural Heart Disease
}

Editors

AMIN AL-AHMAD

FRANCIS E. MARCHLINSKI

\section{CARDIAC \\ ELECTROPHYSIOLOGY \\ CLINICS}

www.cardiacEP.theclinics.com

Consulting Editors

RANJAN K. THAKUR

ANDREA NATALE

March 2017 • Volume 9 • Number 1 